\title{
Safety and feasibility of subarachnoid block in laparoscopic cholecystectomy
}

\author{
Mahmud Ekram Ullah ${ }^{1}$, Md. Mushfiqur Rahman², Rajibul Haque Talukder ${ }^{1}$, \\ Refat Uddin Tareq ${ }^{3}$, Md. Noor A Alam ${ }^{1}$ \\ ${ }^{1}$ Department of Surgery, BIRDEM General Hospital \& Ibrahim Medical College, ${ }^{2}$ Department of \\ Anesthesia, BIRDEM General Hospital \& Ibrahim Medical College, ${ }^{3}$ Islami Bank Hospital
}

\begin{abstract}
Background and objectives: Laparoscopic surgery is normally performed under general anesthesia (GA), but regional techniques like epidural or subarachnoid block (SAB) have been found beneficial in patients having associated major medical problems. In selected cases, it can be a safe alternative to GA. Hence, the present study was conducted to explore the safety and feasibility of SAB in otherwise healthy individuals undergoing laparoscopic cholecystectomy.

Methods: Forty patients undergoing elective laparoscopic cholecystectomy and fulfilling specific inclusion criteria were included in the study. All patients received a segmental (L2-L3 injection) SAB with $3 \mathrm{ml}(0.5 \%)$ of bupivacaine and 25 microgram of fentanyl. Laparoscopic cholecystectomy was done by standard 4 port technique. Intra-abdominal pressure was kept low at 9-10 mm Hg using $\mathrm{CO}_{2}$ pneumoperitoneum. Patients were followed up at 30 minutes, 4 hours, at the time of discharge and on day 7 after operation. Any unwanted voluntary or involuntary movement or exaggerated diaphragmatic excursion during the operation was monitored. Operation time, operating room (OR) occupancy time, hospital stay, post-operative pain, analgesic requirement, nausea, vomiting, headache, right shoulder pain, wound-related complications and patient satisfaction were recorded.

Results: SAB was effective for surgery in all 40 patients. Two patients required conversion to general anesthesia for persisting low oxygen saturation. Hypotension was recorded in $23.7 \%$ patients while $10.5 \%$ experienced right shoulder pain. Average operating time was 37.3 minutes (21 - 77 minutes). Awkward movement and exaggerated respiratory excursion was noted in $23.7 \%$ and $18.4 \%$ cases respectively. Only two cases had to undergo (conversion to) GA. Mean period of hospital stay was 29.3 hours. No incidence of any major complication occurred.
\end{abstract}

Conclusion: This study showed that SAB could be used successfully and effectively for laparoscopic cholecystectomy in healthy patients and may be a safe alternative to GA.

IMC J Med Sci 2019; 13(1): 006. EPub date: 05 May 2019

\section{Introduction}

Gall stone disease is prevalent worldwide and cholecystectomy is the treatment of choice for symptomatic cholelithiasis. For the last two decades, laparoscopic cholecystectomy has replaced more invasive open cholecystectomy because of advantages of less tissue trauma, short hospital stay and increased turnover of patients. It is also economical. Laparoscopic cholecystectomy is normally performed under GA, but regional techniques such as low thoracic epidural [1] and spinal block [2] have been usually used to manage

\footnotetext{
Address for Correspondence:

Dr. Mahmud Ekram Ullah, Assistant Professor, Department of Surgery, BIRDEM General Hospital, 122 Kazi Nazrul Islam Avenue, Shahbag, Dhaka 1000.E-mail:drmahmud50@gmail.com
} 
patients with significant medical problems. Until about a decade ago, the world literatures suggested general anesthesia as the only anesthetic option for abdominal laparoscopic surgery. But recently, laparoscopic cholecystectomy performed in selected patients under SAB or epidural anesthesia have been reported [2-5]. These studies have provided preliminary indication of the feasibility of segmental spinal anesthesia in patients undergoing routine laparoscopic cholecystectomy.

Having the experience of performing upper abdominal surgery under SAB in good number of cases and high turnover of laparoscopic cholecystectomy cases in our center, we decided to explore the safety, outcome and feasibility of SAB in healthy patients undergoing laparoscopic cholecystectomy. Operations were performed using low pressure pneumoperitoneum $(9-10 \mathrm{~mm} \mathrm{Hg})$ to avoid excess stretching of the diaphragm and to lower the complications rate of hypercarbia. Certain technical points were modified to avoid complications.

\section{Materials and method}

Forty patients were selected prospectively from the patients with gallstone disease who opted for laparoscopic cholecystectomy. After obtaining written informed consent, patients were enrolled in the study. The study was conducted in BIRDEM general hospital and Islami Bank Hospital, Dhaka from May 2017 to October 2018. Patient aged 2065 years, having BMI $<25 \mathrm{~kg} / \mathrm{m}^{2}$, normal coagulation profile and fulfilled the American Society of Anesthesiologists (ASA) physical status classification I and II were included in the study. Patients with recent history of jaundice, previous history suggestive of cholangitis or bile duct stone, acute cholecystitis, history of previous upper abdominal operations, ultrasonography features of edematous/thick $3+\mathrm{mm}$ gallbladder wall and suspected gallbladder malignancy were excluded from the study. Patients having contraindication for $\mathrm{SAB}$ were exempted as well.

All patients were kept overnight fasting and preloaded with intravenous (IV) fluid. Under full aseptic precaution standard spinal puncture was done with 25G spinal needle in L2-L3 intervertebral space in sitting position. Three milliliter of $0.5 \%$ bupivacaine +25 microgram fentanyl was injected after confirming free flow of CSF. Head was tilted down to 10 degrees and was kept for 6 to 8 minutes to achieve desirable segmental block at T4-T5 level. Anesthesia level was checked with pin prick sensation. After adequate block the patient was sedated with $25 \mathrm{mg}$ pethidine and 0.5 $\mathrm{mg} / \mathrm{kg}$ ketamine in IV route. Standard pulseoximeter was used for monitoring pulse and oxygen saturation. $\mathrm{CO}_{2}$ pneumoperitoneum was done and intra-abdominal pressure was kept at 9-10 $\mathrm{mm} \mathrm{Hg}$. The patient was positioned to reverse Trendelenburg position with left lateral tilt. Blood pressure was monitored manually at five minutes interval. Any hypotension was managed with extra IV fluid infusion. Injection ephedrine (5 $\mathrm{mg})$, single dose, per-operatively, was given intravenously in patients with systolic blood pressure falling more than $20 \mathrm{~mm}$ of $\mathrm{Hg}$ from baseline value even after adequate intravenous fluid infusion. The surgeons were prepared to ask for general anesthesia if they felt that the anesthetic technique was causing technical difficulty of the procedure.

Laparoscopic cholecystectomy was done by standard four port technique. After pericholecystic adhesiolysis (if any) Callot's triangle was dissected and cystic duct and artery were identified and skeletonized. Both the structures were clipped separately and then divided. Gall bladder was then dissected free off the under surface of liver. Hemostasis was ensured and gall bladder delivered through umbilical port which was then closed in layers. Local anesthetic xylocaine $2 \%$ was injected in all port sites.

Any unwanted voluntary or involuntary movement or exaggerated diaphragmatic excursion from too rapid/ heightened respiration that impeded surgeon's work was monitored. Operation time, operating room (OR) occupancy time, hospital stay, post-operative pain and analgesic requirement, nausea and vomiting, headache, right shoulder pain, wound-related complications and patient satisfaction were noted. They were followed up at 30 minutes, 4 hours, at the time of discharge and on day 7 after operation. The patients were allowed to leave hospital once they passed urine, could comfortably move, had tolerated oral feeding and had been assessed by the surgeon as being free from any complications. 
Pain perception was assessed by verbal rating score (VRS). Patient satisfaction level was determined based upon parameters like management of pain and postoperative nausea vomiting (PONV), quality of life and fulfillment of their expectation on quality of care by the health service providers.

Our endpoint outcome criteria were (1) cardiopulmonary stability in terms of blood pressure, respiration and $\mathrm{O}_{2}$ saturation during intraoperative and immediate post-operative period, (2) pain and PONV within first 4 hours after operation, (3) technical difficulties like space constraint and any unwanted movements of patient that impedes surgeon's work and (4) operating time, operating room occupancy time and hospital stay.

\section{Results}

A total of 40 patients were included in our study. The mean age of the study population was 37.2 years while the range was from 20 to 65 years. Fourteen $(35.0 \%)$ patients were male and 26 $(65.0 \%)$ were female. Mean body mass index was $22.9 \mathrm{~kg} / \mathrm{m}^{2}$ (range $19.3-24.7 \mathrm{~kg} / \mathrm{m}^{2}$ ). Out of 40 cases, $13(32.5 \%)$ had diabetes mellitus. Detail characteristics are shown in Table-1.

Table-1: Baseline characteristics of the study population.

\begin{tabular}{ll}
\hline Parameter & Values \\
\hline Total no of patients & 40 \\
Age in yrs (Mean, range) & $37.2(20-65)$ \\
Sex (Male : Female) & $1: 1.86$ \\
BMI kg/m² (Mean, range) & $22.9,(19.3-24.7)$ \\
Number of cases having & \\
$\quad$ COPD & $3(7.5 \%)$ \\
$\quad$ Hypertension & $7(17.5 \%)$ \\
$\quad$ Diabetes mellitus & $13(32.5 \%)$ \\
\hline
\end{tabular}

Two patients had to undergo general anesthesia later due to persistent low oxygen saturation possibly due to adverse effect of sedative drugs. So ultimately, laparoscopic cholecystectomy under spinal anesthesia was completed in 38 patients. Details of the spinal anesthesia and clinical conditions during the anesthesia of the cases are shown in Table-2. Blood pressure was maintained at normal range in 29 cases, but nine patients developed hypotensive episodes. Six patients were managed with additional IV fluid alone. Three patients needed injection ephedrine $5 \mathrm{mg}$, intravenously, single dose per-operatively along with IV fluid. Oxygen saturation was maintained in all cases around $98 \%$ with oxygen supplementation through nasal catheter if necessary. Operations were performed using low pressure pneumoperitoneum (9-10 $\mathrm{mm} \mathrm{Hg}$ ) to avoid excess stretching of the diaphragm and to lower the complications rate of hypercarbia. In spite of low pressure pneumoperitoneum, we did not have any space constraint or any gastric distension as well. However, two conditions namely - awkward movement in 9 patients and exaggerated respiratory motion in 7 cases were encountered that made the operative field unsteady for a brief period of time (Table-2)

Table-2: Details of $S A B$ and clinical conditions of the cases during operation $(n=38)$.

\begin{tabular}{ll}
\hline Parameter & Values \\
\hline Conversion from spinal to GA & $2(5.0 \%)$ \\
Sensory loss (upper level) & \\
$\quad$ T4 dermatome & $8(21 \%)$ \\
T5 dermatome & $30(79 \%)$ \\
Intra-abdominal pressure & $9-10 \mathrm{~mm}$ of $\mathrm{Hg}$ \\
Oxygen saturation & $97.6 \% ; 96-97 \%$
\end{tabular}

(Mean; range)

Respiratory rate/minute Before pneumoperitoneum 15.3; 14-17 (Mean; range)

During pneumoperitoneum 22.6; 16-34 (mean; range)

Cases with hypotension: SBP $9(23.7 \%)$

fall $\geq 20 \mathrm{~mm} \mathrm{Hg}$

Number of cases managed by

IV fluid only

IV fluid + inj. Ephedrine

$6(15.8 \%)$

$3(7.9 \%)$

Number of cases with:

Awkward movement

Exaggerated respiratory

$7(18.4 \%)$ movement

Note: No cases had gastric distension requiring Ryle's tube or had inadequate intra-abdominal space/ access.

The duration of operations (skin incision to skin closure) was 21 to 77 minutes (mean $37.3 \mathrm{~min}$ ). In 
three patients, wall of gallbladder was perforated during dissection. Saline irrigation and aspiration of the sub-hepatic space was done for bile spillage. In one case, stones were spilled out during dissection which was retrieved in an endobag. No other major complication was encountered (Table-3).

Table-3: Operation details of cases by laparoscopic cholecystectomy under $S A B(n=38)$.

\begin{tabular}{ll}
\hline Parameters & Values \\
\hline $\begin{array}{l}\text { Cases converted to open } \\
\text { cholecystectomy }\end{array}$ & 0 \\
$\begin{array}{l}\text { Operating time (minutes) } \\
\text { (mean and range) }\end{array}$ & $37.3 ; 21-77$ \\
$\begin{array}{l}\text { OR occupancy (minutes) } \\
\text { (mean and range) }\end{array}$ & $45.6 ; 30-89$ \\
$\begin{array}{l}\text { Adhesions (gallbladder) } \\
\text { Gallbladder perforations }\end{array}$ & $10(26.3 \%)$ \\
during dissection & $3(7.9 \%)$ \\
$\begin{array}{l}\text { Gallstone spillage } \\
\text { Gut injuries }\end{array}$ & $1(2.6 \%)$ \\
Bile duct injuries & 0 \\
\hline
\end{tabular}

Note: OR=Operation room

Conditions observed during follow up at different time intervals are shown in Table-4. All patients were followed up at 30 minutes, at 4 hours, at the time of discharge and on the $7^{\text {th }}$ day after operation. Almost all patients were hemodynamically stable and maintained full $\mathrm{O}_{2}$ saturation $(98.2,97-99 \%)$ in the early post-operative period. Incidence of nausea, vomiting and headache was very low. Only two patients complained of post-spinal headache, especially where first spinal puncture was unsuccessful. Only one patient developed nausea and vomiting. No patient required injectable analgesic for surgical site pain within 4 hours. Four patients complained of right shoulder tip pain which was severe in one case. Those patients were managed by continuous finger massaging by a nurse over the right shoulder area of the patients. All patients tolerated oral feeding at 6 hours and most of them were discharged from the hospital within 24 hours of operation after assessing them to be free from complication. Mild purulent discharge from umbilical wound was noted in two cases on first follow-up. The wounds healed up spontaneously on dressing. All the patients were satisfied with results of operations. No patient complained against any step of anesthesia or the operation during follow up.

Table-4: Conditions of the patients observed during follow up at different time intervals $(n=38)$.

\begin{tabular}{ll}
\hline $\begin{array}{l}\text { Conditions observed during } \\
\text { follow up }\end{array}$ & $\begin{array}{c}\text { Number } \\
(\%)\end{array}$ \\
\hline $\begin{array}{l}\text { At } 30 \text { minutes } \\
\text { Hypotension } \\
\text { (SBP fall } \geq 20 \mathrm{~mm} \text { of Hg) }\end{array}$ & $2(5.3 \%)$ \\
Nausea/ vomiting & $1(2.6 \%)$ \\
Post-spinal headache & $2(5.3 \%)$ \\
Right Shoulder pain & $4(10.5 \%)$ \\
Surgical site pain requiring & 0
\end{tabular}

injectable analgesic

\section{At 4 hours}

Post-spinal headache

Nausea/ vomiting

0

Surgical site pain requiring injectable analgesic

Right shoulder pain

$\begin{array}{ll}\text { At discharge } & 0 \\ \text { Bile leakage } & 0 \\ \text { Jaundice } & 0 \\ \text { Peritonitis } & \\ \text { Patient satisfaction } & 25(65.8 \%) \\ \quad \text { Highly satisfied } & 13(34.2 \%) \\ \text { Satisfied } & 0 \\ \quad \text { Not satisfied } & 29.3 ; 21-53\end{array}$

Hospital stay in hrs (mean; range)

\section{At day 7 follow up}

Port site infection (Umbilical)

Bile leakage

Jaundice

0

0

Peritonitis

\section{Discussion}

Laparoscopic cholecystectomy is the gold standard for the treatment of uncomplicated symptomatic cholelithiasis. General anesthesia is regarded as safe and most widely practiced anesthesia for laparoscopic surgery in almost all of these cases. Regional anesthesia was seldom used in abdominal laparoscopic surgery except for diagnostic procedures [5]. The prime indication for using 
regional anesthesia in therapeutic laparoscopy is still limited. The preferred type of regional anesthesia is epidural anesthesia [1]. Thus, reports of laparoscopic cholecystectomy using subarachnoid block are limited [2-6].

Single puncture SAB is an easier and more cost effective technique than general anesthesia [7]. Complication of endotracheal intubations such as damage to oral cavity, teeth, sore throat, aspirations, failure of intubations, gastric distension are absent in spinal anesthesia. Therefore, monitoring of patients under $\mathrm{SAB}$ is relatively easy compared to general anesthesia. Nausea and vomiting are less with SAB [8]. Laparoscopic cholecystectomy with low-pressure pneumoperitoneum under $\mathrm{SAB}$ is effective in patients with COPD, who are unsuitable for GA $[9,10]$.

Using low pressure $\left(\begin{array}{lllll}9-10 & \mathrm{~mm} & \mathrm{Hg} & \mathrm{CO}_{2}\end{array}\right.$ pneumoperitoneum during $\mathrm{SAB}$ for laparoscopic cholecystectomy have been reported to reduce the abdominal discomfort and chances of neck and right shoulder pain [11]. In our cases, operation was performed at an average pressure of $9-10 \mathrm{~mm}$ $\mathrm{Hg}$ using $\mathrm{CO}_{2}$ and no changes were necessary in port placement. Pursnani et al reported shoulder and neck pain in 2 out of 6 patients operated under SAB [10]. Surprisingly, right shoulder pain had never been a major problem in the present study. It occurred only in $10.5 \%$ patients and was managed by shoulder massage. In a study of 310 laparoscopic cholecystectomy cases performed under spinal anesthesia, only one patient needed conversion to GA because of intolerable shoulder pain [2]. Reason for conversion in both the cases of our study was persistence of low $\mathrm{SPO}_{2}$ (below 90\%).

Hypotension is a problem of SAB, which can be overcome by preloading with fluids [12]. In addition to spinal anesthesia related hypotension, the pneumoperitoneum induced rise in intraabdominal pressure could be another cause for persistence of hypotension. In spinal anesthesia, hypotension was reported in $5.4 \%$ to $20.2 \%$ cases [13-15] compared to $23.7 \%$ cases in the present study. Lowering of head end of table after Callots' triangle dissection, elevation of foot end of the table during repair of the ports and during postoperative period, as well as low pressure $\mathrm{CO}_{2}$ pneumoperitoneum prevent fall of blood pressure. An added advantage cited was the decrease in surgical bed oozing because of hypotension and bradycardia associated with spinal aesthesia [16]. On the contrary, laparoscopic surgery under general anesthesia is associated with hypertensive episodes which may augment bleeding during dissection causing operation difficult and lengthy; but under spinal anesthesia, there were no such episodes of hypertension in any patient.

The status of respiratory parameters during laparoscopic cholecystectomy done under SAB should be taken into consideration. In this context it can be stated that spontaneous physiological respiration during SAB would always be better than artificial respiration as in general anesthesia. Intubation related morbidity and mortality can be avoided and is one of the most beneficial effects of SAB particularly in patients with poor respiratory reserve [5]. Pulmonary function takes 24 hours to return to normal after laparoscopic surgery performed under general anesthesia [11].

A specific advantage of SAB is less requirement of analgesic during early post-operative period. In a comparative study between $\mathrm{SAB}$ versus GA for laparoscopic cholecystectomy, MM Islam et al [5] reported only $10 \%$ patients in the $\mathrm{SAB}$ group required injectable analgesic against $90 \%$ in the GA group. This was consistent with the findings in our study as none of our patients needed injectable analgesic during first 4 post-operative hours. The problem of PONV was much less $(3.3 \%$ in SAB group vs $20 \%$ in GA group) in the same study which was also supported by our study (only $2.6 \%$ patients).

During the present study, two issues drew our attention from surgeon's point of view that was linked to technical aspect of laparoscopic cholecystectomy under SAB. The surgeon may have to pause for a while during any awkward movement of the patient's body involving upper extremity and/ or trunk that we came across in nine cases. Also, the surgeon may have to adjust for the heightened or faster diaphragmatic respiratory excursion that we encountered in seven patients. However, an experienced and competent surgeon can accommodate these events very well. Secure strapping of the patient and smooth, adequate sedation would help in this regard. Although intra-abdominal space was relatively less $(9-10 \mathrm{~mm}$ $\mathrm{Hg}$ compared to standard $12 \mathrm{~mm} \mathrm{Hg}$ ), it did not hamper any aspects of surgical maneuver. 
The time from application of anesthesia to wheeling the patient out of the operating room actually decreases when the patient is being operated under $\mathrm{SAB}$ as the time for intubation and extubation is saved [5]. SAB appears to be economical as it involves less medicine, decreased operation theater occupancy time, faster recovery and shorter hospital stay.

\section{Conclusion}

This limited study involving 38 patients has provided preliminary evidence that in selected cases, $\mathrm{SAB}$ can be a safe and alternative technique to GA for routine laparoscopic cholecystectomy. However, further careful evaluation of the technique would be desirable and appropriate involving patients with varying types of co-morbidity.

\section{Competing interest: None}

\section{References}

1. Gramatica L Jr, Brasesco OE, Luna AM. Laparoscopic cholecystectomy performed under regional anesthesia in patients with chronic obstructive pulmonary disease. Surg Endosc. 2002; 16: 472-5.

2. Hamad MA, Ibrahim El-Khattary OA. Laparoscopic cholecystectomy under spinal anesthesia with nitrous oxide pneumoperitoneum: a feasibility study. Surg Endosc. 2003; 17: 1426-8.

3. Sinha R, Gurwara AK, Gupta SC. Laparoscopic surgery using spinal anesthesia. J Soc Lap Surg. 2008; 12: 133 - 138.

4. van Zundert AA, Stultiens G, Jakimowicz JJ, Peek D. Laparoscopic cholecystectomy under segmental thoracic spinal anaesthesia: a feasibility study. Br J Anaesth. 2007; 98(5): 682-6.

5. Islam MM, Hossain MI, Tarek MRU, Razon SMH, Ahmed I. Subarachnoid block versus general anesthesia for laparoscopic cholecystectomy A comparative study. J Dhaka National Med Coll Hosp. 2015; 21(2): 38-41.

6. Ciofolo MJ, Clergue F, Seebacher J. Ventilatory effects of laparoscopy under epidural anesthesia. Anesth Analg. 1990, 70(4): 357-361.
7. Yuksek YN, Akat AZ, Gozalan U, Daglar G, Pala Y, Canturk M, et al. Laparoscopic cholecystectomy under spinal anesthesia. Am J Surg. 2008; 195: 533-6.

8. Tzovaras G, Fafoulakis F, Pratsas K, Georgopoulou S, Stamatiou G, Hatizitheofilou C. Spinal vs. general anesthesia for laparoscopic cholecystectomy; interim analysis of a controlled randomized trial. Arch Surg. 2008; 143: 497-501.

9. van Zundert AA, Stultiens G, Jakimowicz JJ, van den Borne BE, van der Ham WG, Wildsmith JA. Segmental spinal anesthesia for cholecystectomy in a patient with severe lungs disease. $\mathrm{Br} J$ Anaesth. 2006; 96: 464-6.

10. Pursnani KG, Bazza Y, Calleja M, Mughal MM. Laparoscopic cholecystectomy under epidural anesthesia in patients with chronic respiratory disease. Surg Endosc. 1998; 12: 1082-4.

11. Putensen-Himmer G, Putensen C, Lammer H, Linqnau W, Aigner F, Benzer H. Comparison of postoperative respiratory function after laparoscopy or open laparotomy for cholecystectomy. Anesthesiology. 1992; 77(4): 675-80.

12. Hirvonen EA, Poikolainen EO, Paakkonen MF, Nuutinen LS. The adverse hemodynamic effects of anesthesia, head-up tilt, and carbon dioxide pneumoperitoneum during laparoscopic cholecystectomy. Surg Endosc. 2000; 14: 272-7.

13. Hartman B, Junger A, Klasen J. Incidence and risk factors for hypotension after spinal anesthesia induction: an analysis with automated data collection. Anesth Analg. 2002; 94(6): 1521 - 1529.

14. Palachewa K, Chau-In W, Naewthong P. Complications of spinal anesthesia at Stinagarind hospital. Thai J Anesth, 2001; 27(1): 7-12.

15. Throngumachi R, Sanghirun D, Traluzxamee K,Chuntarakup P. Complications of spinal anesthesia at Lerdsin Hospital. Thai J Anesth. 1999; 25(1): $24-27$.

16. Casey WF, Spinal Anesthesia: A practical guideline. In update in anesthesia, 2000; 12(8): $1-7$. 